\title{
BOLSAS: CRIAÇÃO E PRODUÇÃO DE ESTAMPAS RELACIONANDO DESIGN DE SUPERFÍCIE À CULTURA GAÚCHA
}

\author{
Bags: creation and production of patterns relating to the surface design with the \\ culture gaucha
}

BALESTRIN, Flávia Regina; Especialista em Design de Superfície; Universidade Feevale

\begin{abstract}
Resumo:
O presente estudo propõe o desenvolvimento de uma coleção de estampas que serão aplicadas em bolsas. Tendo como base conceitual, aspectos da cultura e identidade gaúcha, com enfoque no chimarrão. A escolha pela temática é motivada pelo crescente consumismo das massas, que buscam no mercado produtos diferenciados, funcionais e esteticamente significativos. A partir de informações sobre a temática e o enfoque do produto a ser desenvolvido, apresentam-se referências gráficas e visuais, a construção de painéis semânticos, a utilização de técnicas de ilustração, assim como o emprego de recursos gráficos essenciais para a concepção das padronagens. A pesquisa é embasada em autores influentes no design gráfico e de superfície, tais como Renata Rubim (2005), Evelise Anicet Rüthschilling (2008), Dinah Bueno Pezzolo (2007), Ada Raquel Doederlein Schwartz (2008), entre outros, fundamentando os conceitos que envolvem o desenvolvimento e a aplicabilidade de estampas para diferentes superfícies.
\end{abstract}

Palavras-chave: Design de Superfície, Estampas, Bolsas, Cultura Gaúcha

\begin{abstract}
:
This study proposes the development of a collection of prints which will be applied in bags. Having as a conceptual basis, aspects of culture and Gaucho identity, focusing on mate. The choice of topic is motivated by the growing consumerism of the masses, who seek to market differentiated, functional and aesthetically significant products. From information on the theme and focus of the product to be developed, we present graphical and visual references, the construction of semantic panels, the use of graphic techniques, as well as the use of graphic resources essential for the design of patterns. The research is grounded in influential graphic design and surface, such as Renata Rubim (2005), Anicet Evelise Rüthschilling (2008), Dinah Pezzolo Bueno (2007), Ada Doederlein Rachel Schwartz (2008), among others, basing concepts involving the development and applicability of prints for different surfaces.
\end{abstract}

Key-words: Surface Design, Patterns, Bags, Gaucho Culture 


\section{INTRODUÇÃO}

O design exerce papel importante no desenvolvimento humano, observamos a incessante modernização de produtos e uma inquieta demanda conceitual. As superfícies dos objetos, por exemplo, sofrem interferência sistemática através do homem, desde os povos mais antigos. Ainda hoje encontramos artigos distintos de cada época ou de cada povo, fazendo algum tipo de participação em nosso cotidiano, de forma peculiar e até mesmo com algum tipo de linguagem própria como forma de diferenciação. A padronagem referida a cada uma destas superfícies aguça tanto nosso senso emocional quanto sensorial e sem que percebamos, estamos em contato constante com a sua simbologia. Cores, formas, padrões e texturas fazem parte deste meio, seja ele pertencente ao humano, a fauna ou a flora, por exemplo. Deste modo, o presente estudo propõe-se a desenvolver uma base conceitual entre a cultura gaúcha, simbolizada neste estudo pelo chimarrão, bebida símbolo do Rio Grande do Sul, e pelo design de superfície, com a intenção de desenvolver uma coleção de estampas que serão aplicadas em modelos específicos de bolsas.

O Rio Grande do Sul é rico em referências culturais e históricas. Além da dança, do churrasco e das atividades pecuaristas o povo gaúcho mantém a tradição do chimarrão, que é também um convite hospitaleiro aos que chegam ao estado. Típica do sul do país e de grande parte da América do Sul, a bebida popularizou-se não somente entre os gaúchos mas entre brasileiros que o provam. E apresenta-se com o desafio de ser o enfoque e a referência máxima na criação das estampas que ilustram a coleção de bolsas apresentadas nesta pesquisa.

A escolha por sacolas estampadas surge a partir de uma reflexão sobre o estado atual a qual se encontra o meio ambiente. Algumas nações já estão mudando a sua maneira de agir e consequentemente provocando mudanças culturais. O que de fato buscamos é uma maneira de aliar o politicamente correto a produtos práticos, úteis, modernos e que traduzam nosso estilo pessoal. As sacolas retornáveis já existiam nos anos 70, porém eram simples e sem detalhes estéticos. O problema instaurado acerca do meio ambiente fez com que designers pensassem em soluções racionais, fomentando a ideia da reutilização das sacolas, no entanto com estampas mais atrativas.

A ideia da reutilização atrelada ao estilo espalhou-se de forma rápida e ilimitada, podendo ser utilizadas conforme o local ou ocasião. E com este propósito a pesquisa a seguir visa a aplicabilidade das estampas desenvolvidas em modelos concebidos para usos diversos, no entanto há um modelo com uma finalidade bem específica, considerada como carro-chefe e norteador deste projeto. Esta bolsa é diferenciada das demais e sua utilização é bem difundida entre os gaúchos, recebendo carinhosamente o nome de "mateira" por servir estritamente para carregar o "kit" de chimarrão. É importante salientar que as estampas criadas serão aplicadas em modelos de bolsas que dão ao usuário a liberdade de escolher a melhor maneira para utilizar o produto.

\section{REFERENCIAL TEÓRICO}

O referencial teórico aborda os temas pertinentes a esta pesquisa, de modo a gerar subsídios para a etapa de criação de estampas aplicadas em bolsas, tendo início no design, ao qual possui uma ampla perspectiva, e então dará abertura a uma área 
mais específica que é design de superfície. O mesmo, aliado a cultura e ao tradicionalismo gaúcho, tão presente e imponente Rio Grande do Sul e na nossa própria identidade, possibilitou o desenvolvimento deste estudo.

\subsection{Design: alguns aspectos históricos}

Para Gordon (2012), na prática, o design faz parte de um universo considerável frente as artes, ciências humanas e exatas, o que permite que a criatividade permeie entre a técnica e o conceito. Visa comunicar ideias e conceitos assim como conciliar funcionalidade, planejamento, personalidade, criatividade e viabilidade resultando em produtos esteticamente atraentes além de serem capazes de sanar as necessidades do cotidiano. Quando o Design desempenha um papel transmissor e formador de opiniões, já que está presente em produtos (visuais ou objetos), estabelecendo relações sociais e marcando a atuação das pessoas na sociedade. Criar significados e conseguir transmiti-los, estimula o receptor a estabelecer uma relação com o que foi produzido.

Medeiros (2012) acrescenta que atualmente o design possui várias vertentes tornando-se difícil delimitar a atuação do profissional da área, sobretudo é necessário que o designer alcance, absorva, sobreponha e reflita sobre todas as possibilidades de criação. A solidificação e aprimoramento profissional recebeu apoio sobretudo da escola de arte alemã Bauhaus, fundada em 1919. A escola incentivava e introduzia aos estudantes conceitos do design mas buscava primordialmente a liberdade criativa dos mesmos. Rejeitando a ornamentação em favor da funcionalidade, a Bauhaus era um movimento altamente politizado, com um caráter radical que muitos consideravam socialista.

Segundo Agostini (2012), a Bauhaus abriu precedentes para novas formas de pensar e aplicar o design, porém explanou apenas algumas das ideias essenciais para o sucesso teórico do design no desenvolvimento industrial. Com o objetivo de ensinar, pesquisar e desenvolver com mais afinco a área do design, é inaugurada a escola de Ulm, que destaca-se como um dos mais imponentes centros do design internacional, sendo o responsável pela experiência mais significativa do movimento no período pós Segunda Guerra Mundial, e embora estivesse sob forte influência da Bauhaus, Ulm tendia no seu início, mais para a estética do que para a técnica propriamente dita. Constatando que a ideia primordial é atuar na concepção de ampla gama de objetos produzidos em escala industrial, de uso cotidiano ou científico, fazendo a ligação entre os suportes modernos de informação, às mídias e à publicidade.

\subsection{Design gráfico}

Conforme Consolo (2009), dentre as diversas áreas do design, o gráfico surge como um tradutor visual dentro da comunicação. O profissional da área aborda meios concretos para informar, projetar, estruturar, processar e transmitir uma dada mensagem.

\subsection{Cultura}

A cultura de uma forma genérica, está fundamentada na sua lógica interna tal qual ao que diz respeito a história da humanidade e aspectos da vida social de alguma nação ou grupo específico, assim como na sua abundância de informações e principalmente transformações. Para Gomes $(2005$, p. 2) o raciocínio com a ideia de 
que "cultura é uma memória social, isto é, um depósito de informações históricas para as futuras gerações e sociedades". Em diversas situações a cultura surge como mediadora destas relações sociais.

\subsection{Cultura e tradicionalismo gaúcho}

Para Oliven (1993), em uma determinada região são projetados valores, memórias e tradições, de modo a formar uma identidade cultural dos indivíduos que ali habitam. Há no território gaúcho, por exemplo, um estereótipo mental fortemente consolidado, formado por personagens, símbolos, práticas sociais, ritos, crenças, valores diversos e manifestações artísticas. No Brasil, as identidades regionais podem ser justificadas pelo resultado da homogeneização cultural, mas é importante ressaltar que o sincretismo cultural não aconteceu naturalmente; foi parte resultante da tentativa de criação de uma nova identidade nacional. Deste modo, a identidade gaúcha torna-se resposta não mais nos termos da tradição farroupilha, mas enquanto expressão de uma distinção cultural através de crenças, danças típicas, culinária, a lida no campo, hábitos como o mateado, por exemplo. De acordo com, os tradicionalistas se constituem em um movimento organizado e atento a tudo que diz respeito aos bens simbólicos do Estado sobre os quais procuram exercer seu controle e orientação. Por fim, o surgimento da tradição gaúcha ocorre numa época em que o Brasil se encontra integrado do ponto de vista político, econômico, cultural e de redes de transportes e de comunicações. Esse movimento tradicionalista ocorre não somente quando o Brasil já está consolidado enquanto nação, mas também quando o Rio Grande do Sul é predominantemente urbano e fortemente industrializado, o que mostra que as tradições florescem em situações de modernização.

\subsection{0 chimarrão}

O chimarrão ou mate, como é habitualmente chamado é bastante estimado, pelo povo gaúcho. É um dos elementos que mais representa o Rio Grande do Sul, da mesma forma como a araucária, a bela e delicada flor-brinco-de princesa, o chá macela, o churrasco, o pássaro quero-quero. Segundo Tubino (2011) o ato de matear, é uma prática hospitaleira e de acolhimento fraterno. O seu preparo não necessita de grande cerimônia e sim de uma cuia, uma bomba, erva-mate de qualidade e água quente. Acredita-se que o termo chimarrão ou mate tenha origem na língua quíchua, que denomina o porongo de "matty". O chimarrão é preparado a partir da infusão da erva-mate, planta constituída exclusivamente pelas folhas e ramos das variedades de llex paraguariensis, na forma inteira ou moída, obtida através de tecnologia apropriada.

\section{DESIGN DE SUPERFÍCIE}

A ideia de estampar vestimentas, objetos e até a própria pele é tão antiga quanto comum em diversas culturas, atualmente é encontrada de forma abrangente em todo o planeta. Estampar o próprio corpo foi o primeiro passo, sendo seguido pelo surgimento das vestimentas, que faziam-se necessárias devido as baixas temperaturas. Antigamente as fibras naturais e macias inspiravam as tramas de tecidos, que serviam ao homem de diversas maneiras. Alguns eram destinados a vestimentas, outros no entanto, devido a sua resistência eram utilizados exclusivamente para guardar e transportar mantimentos, com o tempo passaram a ser utilizados como bolsas ou 
sacolas para objetos pessoais. A autora Pezzolo (2007) afirma que o processo de tingimento destes tecidos dava-se de maneira natural e os corantes eram oriundos do barro e de seivas naturais. As primeiras matrizes utilizadas para a estamparia de tecidos foram as próprias mãos seguido de pedaços de madeira como forma de carimbos. Pelos de animais atados a pedaços de madeira foram inseridos neste contexto com a intenção de serem utilizados como ferramentas, dando a ideia dos primeiros pincéis.

Deste modo, a superfície recebe texturas, estampas, desenhos, cores e nuances que a torna especial. E a crescente demanda de projetos no setor sugere que este seja outro campo a ser explorado de forma significativa. Este novo campo de atuação recebe o nome de design de superfície, tradução para Surface Design, termo utilizado em países de língua inglesa. Para Pezzolo (2007), na prática é possível pensar além da área externa dos corpos ou objetos e criar superfícies com estampas de repetição ou até mesmo com combinação de módulos contínuos. Claramente um bom projeto de design de superfície está atrelado a uma proposta conceitual tangível entre a linguagem visual e tátil a partir dos elementos compositivos (como cor, forma, textura e ritmo), bem como é importante levar-se em consideração as questões culturais, psicológicas e sociais, propondo um argumento estético à superfície em questão.

Para Rubim (2010) O design de superfície no entanto propõe-se a lidar com ideias de ordem puramente estética. Seu processo criativo é voltado para aplicação na indústria, e abrange basicamente o design têxtil, o setor de papelaria, cerâmica, plásticos, madeira, emborrachados, couros e peles diversas, materiais sintéticos entre outros. Cada projeto possui características próprias para execução e deve respeitar algumas normas técnicas. Deve-se considerar antes de criar um motivo para estamparia, as dimensões por exemplo, a familiaridade do designer com ferramentas de desenho e o número de cores que serão utilizadas bem como as tecnologias disponíveis na indústria para a sua execução.

\subsection{Fundamentos básicos do design de superfície}

Embora haja metodologia adequada para a execução projetual, existem também aspectos físicos e estruturais, a tecnologia e materiais empregados e até mesmo as necessidades do mercado. Em muitos projetos de design a maneira como os elementos estão dispostos ditam o seu sucesso ou fracasso, e então percebe-se nitidamente o apelo visual e tecnológico empregado pelo designer como forma de expressão. O designer de superfície deve ter a noção imprescindível de questões relacionadas ao módulo e a repetição (RUBIM, 2010). O formato do módulo determina seu tipo de ocupação em uma superfície. No entanto, como estamos nos referindo a produção têxtil, pressupõe-se que seu formato seja quadrado ou retangular, devido a resquícios tradicionais do setor, onde sua medida era feita conforme o tamanho a partir do comprimento e largura do tecido a ser estampado.

Segundo Udale (2009), para a construção de estampas contínuas é necessário utilizar noção de módulo e como se dá a sua construção. Noção de repetição, também conhecido por rapport, e seus sistemas combinatórios. A autora segue apontando demais princípios básicos: a) escala: tamanho do motivo em proporção à aplicação na peça final; b) padronagem e repetição: como o design flui na peça, se há uma direção, uma parte superior ou inferior; c) posicionamento: o local onde será aplicada uma estampa e a sua reprodução industrial; d) cores e esquema de cores: seleção de uma 
paleta de cores baseada no tema da coleção; e) peso, textura e superfície: analisar o peso do tecido e sua interferência na aplicação do design, e se uma textura beneficia a composição final. Neste ponto, o peso do fio e o tamanho e tipo de ponto ou da trama afetam a textura.

Ruthschilling (2008) acrescenta que a organização dos elementos ou motivos gera a composição da imagem dentro de uma estrutura preestabelecida, que garante os princípios de proximidade e continuidade. De maneira que, quando repetidos lado a lado e em cima e embaixo, os módulos formam um padrão contínuo. Lupton e Phillips (2008) fomentam o princípio modular afirmando que este é na verdade um tipo de restrição do design de superfície que possui um potencial desafiador perante a criatividade do designer. É necessário solucionar a problemática modular unitária para só então resolver o módulo de forma conjunta (fig. 1). A composição de uma estampa contínua ocorre em dois níveis: primeiramente dentro do módulo (pela organização das formas), e depois quando gera-se o padrão (de acordo com a estrutura de repetição do módulo). O sistema de repetição do módulo (rapport em francês ou repeat em inglês) é o que rege a lógica por trás da grade organizacional modular.

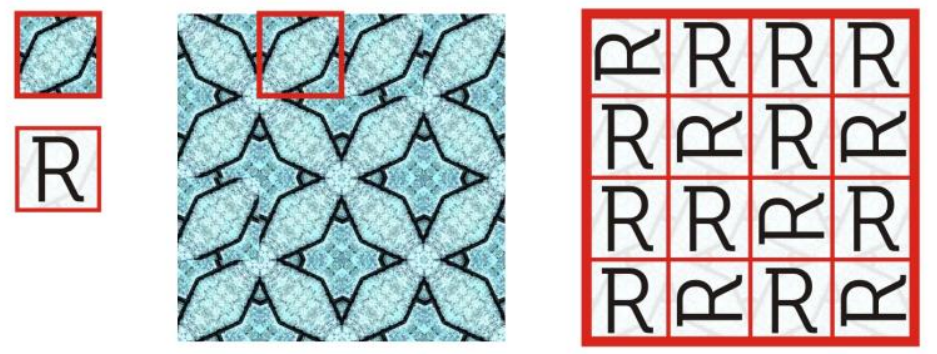

Figura 1 - Módulo e padrão gerado a partir de organização modular Fonte: Elaborado pelo autor, com base na pesquisa realizada

A pesquisadora Ruthschilling (2008) explica que o sistema modular pode ser alinhado, não-alinhado ou progressivo. No primeiro caso, as células repetem-se sem deslocamentos de origem, que é o ponto a partir do qual o criador considera o início da composição visual do módulo, coincide com a zona de encaixe entre módulos ou intersecção entre a grade e o módulo. Nesse sistema, pode haver variação da posição do módulo dentro da célula, pelo movimento de: translação (mantém a direção, mas desloca-se sobre um eixo), rotação (desloca-se radialmente ao redor de um ponto), e reflexão (espelhamento). Já o sistema não-alinhado é mais complexo, pois, além de permitir os movimentos dos módulos, possibilita o deslocamento de origem das células, sendo mais comum o deslocamento de 50\%, gerando o efeito "tijolinho".

Freitas (2011) compreende este recurso como um facilitador visual de grandes formatos. E finalmente, o sistema progressivo permite dilatação ou contração das células, obedecendo uma lógica pré-determinada pelo designer. Conforme Schwartz (2008) quando o rapport é construído por meio simétrico e compreende mais de um módulo gera-se a partir dele um multimódulo. Igualmente, vê-se a possibilidade de trabalhar composições sem encaixe que podem gerar fluência e ritmo visual. Em propostas deste tipo podem surgir problemas, e é de suma importância que o projetista esteja atento a concepção destes padrões. Módulos com encaixes imperfeitos tendem a acumular espaços vazios. 


\subsection{Processos de impressão em tecidos}

O homem já fez uso das mais diversas técnicas para estampar e colorir seus tecidos (PEZZOLO, 2007). A prática da estamparia permeou entre técnicas manuais de tingimento, até chegar nos recursos atuais. A superfície se faz expressiva ao passo que transmite a particularidade do indivíduo em termos de aparência e função, o que pode envolver uma infinidade de formas, passando por variados processos de tratamentos em estamparia, tinturaria e, também, com a adição de elementos como bordados e aviamentos. Há que se considerar em um projeto de superfície têxtil, o tipo de técnica que melhor se adapta ao tecido que se está trabalhando. As técnicas aplicadas podem ser subdivididas basicamente em três grupos: artesanais/manuais, mecanizadas e digitais.

Conforme as autoras Chataignier (2006) e Udale (2009) há diversas técnicas de estampagem artesanal: a pintura manual (pincel direto sobre o tecido), o batik (desenho feito manualmente à cera quente sobre o tecido, isolando as áreas que não receberão corante), bloco de madeira (xilogravura), tye die (consiste em amarrar o tecido aleatoriamente e tingí-lo quimicamente), estêncil (desenho em molde vazado) e ikato (consiste no tingimento do fio antes de sua tecelagem). Referente ao processo industrial, os mais utilizados são os cilindros (rolos que transferem o desenho sob pressão, sendo um para cada cor sobre o tecido estendido em uma esteira rolante); quadro (serigrafia ou silkscreen - exige separação de cores); e o transfer (termoimpressão ou termotransferência) e sublimação, em que a estampa é impressa em papel especial e quando colocado sobre o tecido e submetido ao calor e pressão transfere o corante, para o tecido.

O terceiro sistema é o digital, e segundo Udale (2009), diferencia-se do modo manual por permitir ao designer têxtil trabalhar diretamente do computador para o tecido. É possível criar imagens de alta definição e imprimir muitas cores. Além disso, infinitas camadas e complexas imagens tridimensionais podem ser inseridas em um design. A padronagem repetida pode ter qualquer tamanho e não ficar restrita ao tamanho da tela. O método, além de possibilitar a tiragem de amostras em pequenas quantidades permite a impressão de longas metragens por meio de pigmentos (cartuchos CMYK - ciano, magenta, yellow e black - respectivamente), (CHATAIGNIER, 2006 e PEZZOLO, 2007).

\section{BOLSAS: DESENVOLVIMENTO E APLICAÇÃO DAS ESTAMPAS}

A cadeia produtiva têxtil é ampla e explora os mais variados segmentos. Deste modo analisaremos a seguir questões práticas e pertinentes ao estudo de possibilidades e desenvolvimento das estampas. Além de explanar a história das bolsas, e abordar questões como a relação com o meio ambiente, os painéis utilizados para a criação das estampas, os estudos aprofundados acerca do desenvolvimento de cada etapa e o resultado final.

\subsection{A história das bolsas}

Para Costa (2010, p. 15) há anos a humanidade transporta seus objetos em algum tipo de bolsa, transformando o acessório em "símbolos de épocas e modos de viver". Segundo Thomas (2008), elas são elaboradas com diversos materiais, e nos mais diferentes formatos. Seu emprego era bastante difundido entre povos da Grécia e Roma, por exemplo. Os nômades ao redor do mundo usavam bolsas para transportar 
seus pertences nos lombos de animais. $O$ acessório era utilizado pelos homens com a finalidade de carregar alimentos ou dinheiro. A peça mais antiga que se tem notícia data a Idade Antiga, chamada de alforje. O século XIX foi o precursor da bolsa de mão, tornando-as indispensáveis.

De acordo com Costa (2010), as bolsas e as malas de viagens passaram a receber maior atenção, tornando-se sofisticadas e arrojadas de modo a serem mais um complemento do que uma necessidade de fato. A Revolução Industrial trouxe consigo uma era onde as bolsas possuíam modelos exclusivos, no entanto houve a sua massificação e o acessório tornara-se mais acessível. Nesta época, e os materiais utilizados para confecção eram os mais variados. As mulheres do início do século XX deveriam manter a elegância, para isso era necessário estar sempre a par do que ditava a moda, e ao longo do século, esta passou buscar inspiração no passado para suprir o desejo feminino. Nos anos 1970 nascia a bolsa estilo sacola, que devido ao fato de ser ampla e espaçosa, possibilitava à mulher carregar tudo o que houvesse necessidade. "Ostentação e exagero são palavras que descrevem de forma clara os estilos que construíram a moda" dos anos 1980 (COSTA, 2010, p. 153). A década de 1990 , foi definitivamente marcada pelo consumismo feminino.

\subsection{Ecobags e o design consciente}

O século XX trouxe consigo a alta tecnologia, viabilizando a criação e popularização de produtos e serviços, o que acarretou sérios problemas ambientais. Com o desenvolvimento econômico, as pessoas passaram consumir com maior frequência. Conforme Barroso (2006) quem mais sofre é o ecossistema, com severas consequências acerca de sua capacidade de regeneração. Antigamente os produtos, principalmente os alimentos perecíveis eram pesados no balcão e em sua maioria, vendidos a granel. Eram embalados em saquinhos de tecido ou enrolados em pacotinhos de papel. O comércio acabou tornando-se o grande propulsor do desenvolvimento das embalagens.

Ao final do século $X X$, a sociedade percebe o resultado maléfico da crescente degradação ambiental. O chamado politicamente correto ganha espaço e fica cada vez mais evidente a preocupação da população em contornar o problema. Deste modo, os fatores socioambientais estão comprovadamente inseridos no cotidiano do consumidor atual (SILVA, 2011). Em virtude da crescente necessidade e conscientização da população renasceu a ideia da reutilização de sacolas e aliado a isso, o desejo de conquistar um estilo próprio, prático, elegante e moderno.

\subsection{Estudos: etapas metodológicas das técnicas empregadas}

A fim de auxiliar a construção das estampas desta pesquisa, foram elaborados Mood Board, com informações acerca da paleta cromática, texturas, elementos gráficos e visuais, ícones da cultura gaúcha, mais especificamente a temática do chimarrão e erva-mate, bem como as técnicas a serem utilizadas, e os modelos de bolsas que receberão as padronagens. O objetivo destes painéis é estruturar de forma clara a construção das estampas e qual deve ser os passos a seguir para o desenvolvimento de cada arte. É importante salientar que os modelos de bolsas foram escolhidos e estudados mediante pesquisa no decorrer do projeto. Da mesma forma, durante o projeto, foi escolhido o tecido para a impressão das estampas de modo que o material fosse mais firme e resistente (fig. 2). 

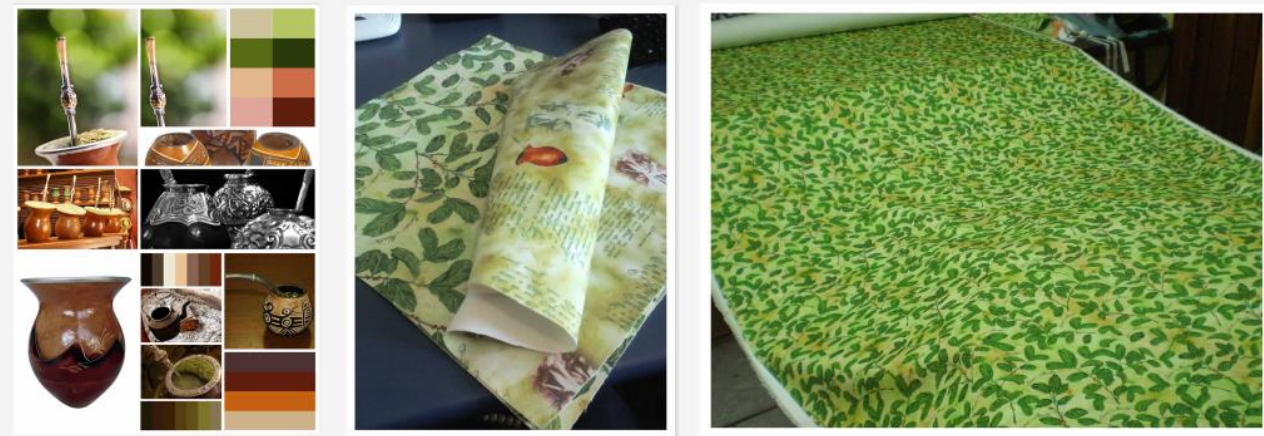

Figura 2 - Mood Board (imagem à esquerda), teste de impressão (imagem central), e estampa impressa em tecido (imagem à direita)

Fonte: Elaborado pelo autor, com base na pesquisa realizada

\subsection{Desenvolvimento e aplicação das estampas}

Com todas as informações reunidas, é possível passar para o desenvolvimento e aplicação das artes ao qual receberam o nome de Erva-Mate, Folhas e Chimarrão e Poesia (fig. 3).

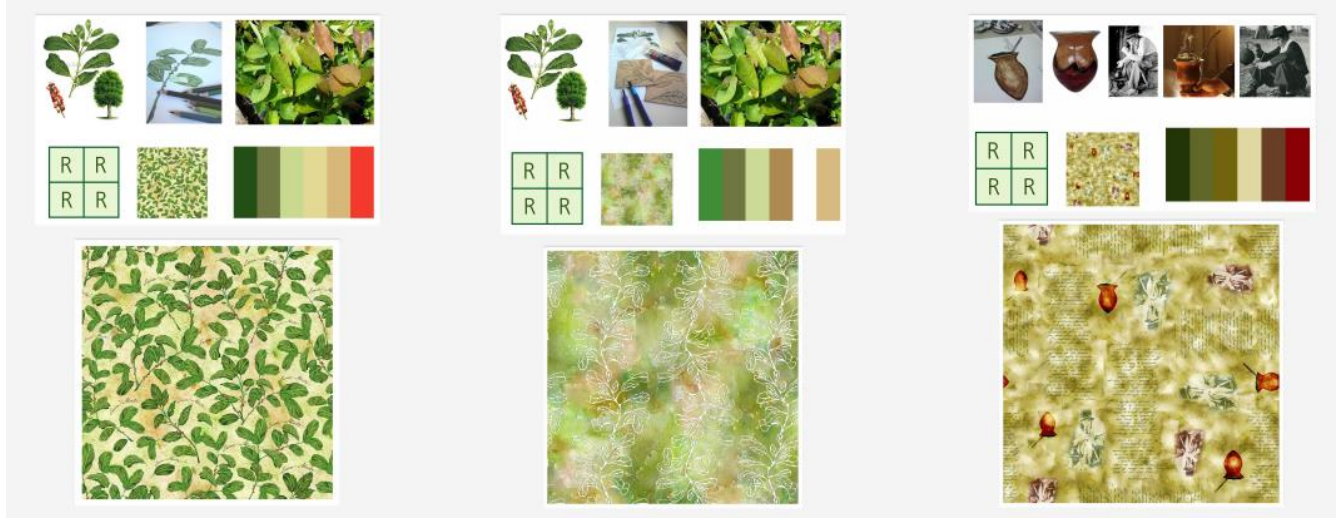

Figura 3 - Estampa Erva-Mate (imagem à esquerda), estampa Folhas (imagem central), e estampa Chimarrão e Poesia (imagem à direita)

Fonte: Elaborado pelo autor, com base na pesquisa realizada

\subsubsection{Estampa Erva-Mate}

A estampa Erva-Mate foi desenvolvida a partir da técnica de ilustração com lápis de cor, buscando um efeito realista. Após a finalização da ilustração fez-se necessário o uso do scanner para transferir a imagem para o computador, onde foram trabalhadas no software Photoshop. Esta padronagem exige maior cuidado ao ser aplicada devido ao fato de haver um direcionamento. Seu rapport foi desenvolvido seguindo os preceitos da translação, de modo que o módulo mantem-se em seu tamanho e direção originais, deslocando-se de uma distância determinada ao longo de um eixo determinado, para direita e esquerda, para cima e para baixo (fig. 4). 

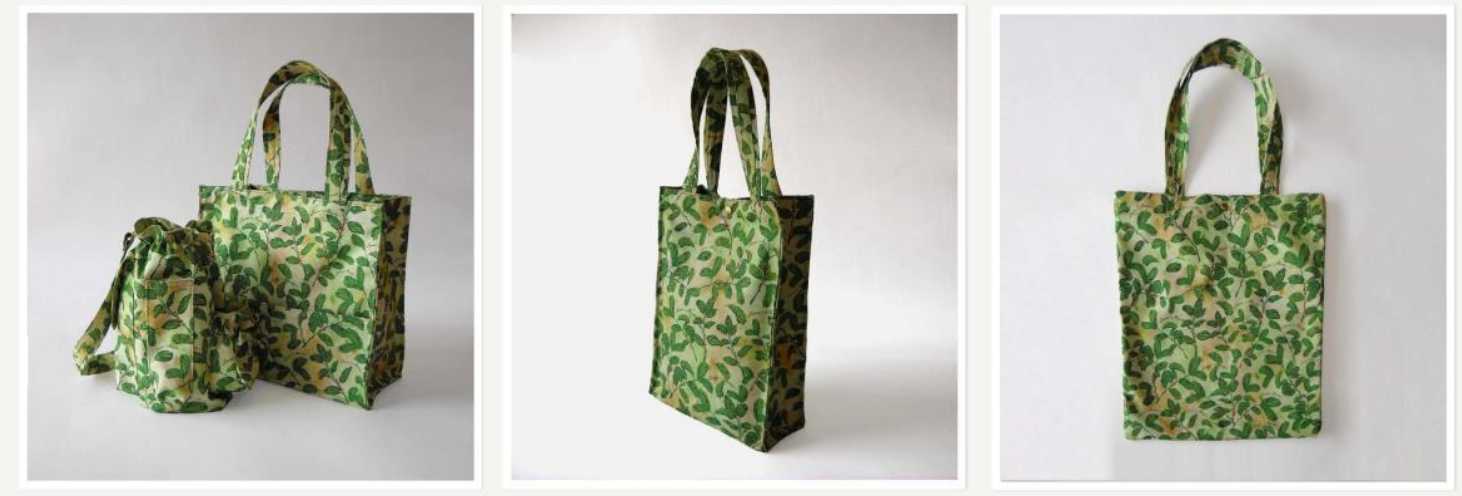

Figura 4 - Bolsas com Estampa Erva-Mate

Fonte: Elaborado pelo autor, com base na pesquisa realizada

\subsubsection{Estampa Folhas}

A estampa Folhas foi criada a partir da técnica de xilogravura. O primeiro passo foi esboçar o desenho de galhos e folhas da erva-mate em papel vegetal. No segundo momento era preciso transferir com o auxílio de papel carbono o mesmo desenho para as matrizes, feitas de placas de MDF nas dimensões de $10 \times 10 \mathrm{~cm}$. Foi necessário fazer alguns retoques e acrescentar pequenos detalhes ao desenho transferido para a madeira. Assim que os desenhos estavam preparados nas matrizes, iniciou-se o entalhe com goivas, ferramentas próprias para a realização da técnica. Em seguida as placas foram entintadas com tinta acrílica escura e prensadas contra o papel. Assim que a tinta estava seca foi necessário digitalizar as imagens. Neste estágio, o objetivo era preservar os detalhes da impressão, para isso o principal tratamento utilizado pelo software Photoshop foi o contraste entre os tons escuros e claros. A orientação do rapport segue alinhado conforme o sistema de translação, porém não há distinção de onde fica a sua base ou o topo do módulo (fig. 5).
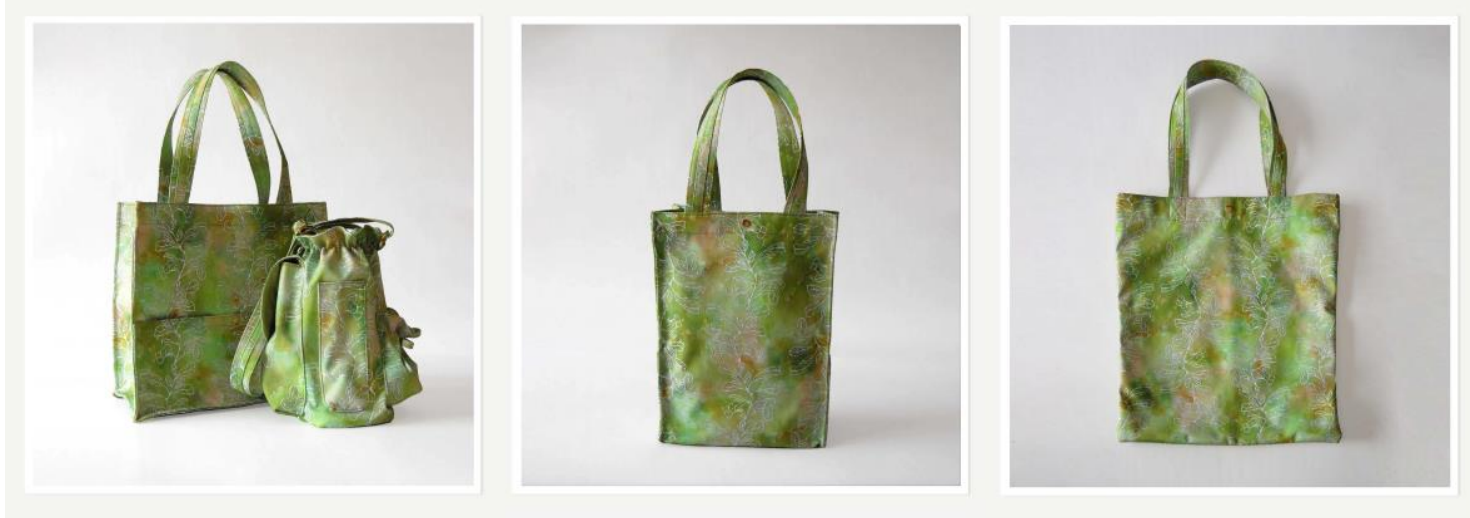

Figura 5 - Bolsas com Estampa Folhas

Fonte: Elaborado pelo autor, com base na pesquisa realizada

\subsubsection{Estampa Chimarrão e Poesia}

Para a construção da estampa Chimarrão e Poesia foi utilizada a técnica da pintura em aquarela. Assim que finalizada a ilustração da cuia de chimarrão, foi necessário digitalizá-la. Como auxílio gráfico, foi aplicado alguns filtros especiais na imagem de um gaúcho mateando. O poema "Chimarrão" de Glaucus Saraiva, lançado 
em 1992, no Livro Poesias, por Apparício Silva Rillo, também fez parte da criação. Os demais ícones e a montagem da estampa foram trabalhados no software Photoshop. Ao contrário das estampas a e b, a estampa c (poesia e chimarrão) pode ser aplicada sem uma direção específica, no entanto, o rapport continua seguindo o sistema da translação, tendo aceitação visual tanto na vertical quanto horizontal, resultando em maior aproveitamento de tecido, ou seja, tornando-se sustentável (fig. 6).
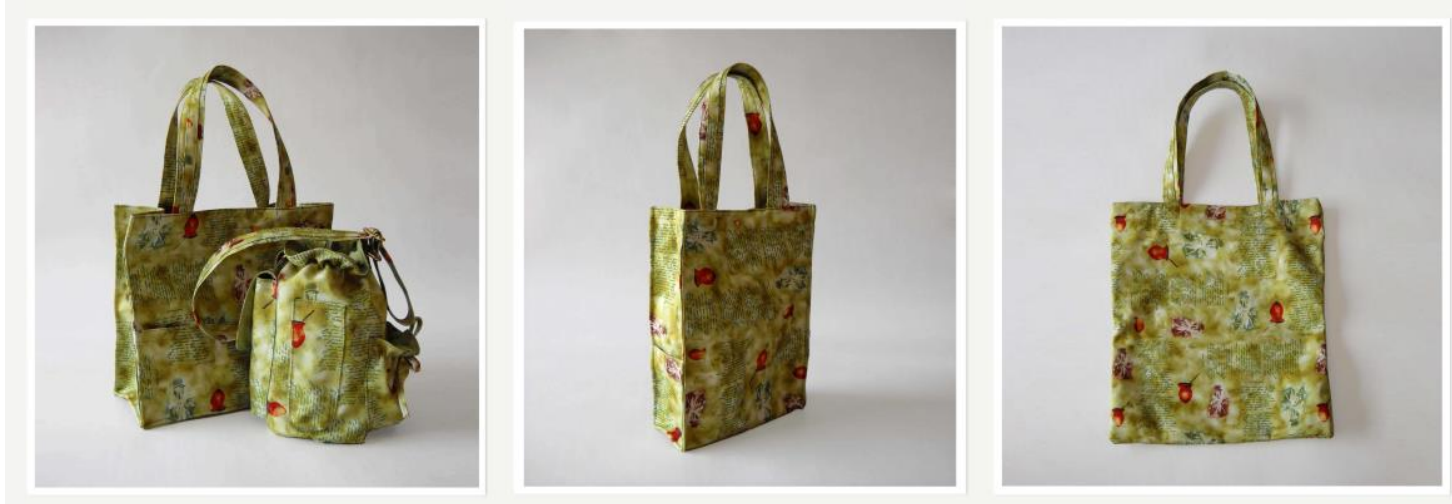

Figura 6 - Bolsas com Estampa Chimarrão e Poesia

Fonte: Elaborado pelo autor, com base na pesquisa realizada

Aliando referências visuais e técnicas foi possível fazer um levantamento das informações disponíveis. Tais elementos possibilitaram também o desenvolvimento de três estampas com características e métodos próprios. As estampas foram aplicadas em modelos de bolsas que dão ao usuário a liberdade de escolher a melhor maneira para utilizar o produto.

\section{CONCLUSÃO}

O estudo sobre o design de superfície bem como a seleção dos ícones que melhor representam o Rio Grande do Sul criaram forte conceituação e um material vasto para a criação das estampas desta coleção. Com o auxílio de um embasamento teórico aprofundado acerca do design de superfície foi possível reproduzir nas estampas, de forma satisfatória, um dos mais imponentes símbolos da cultura gaúcha, o chimarrão. O processo da pesquisa, como um todo, foi muito enriquecedor, exigiu esforço prático e criativo, no entanto, proporcionou grande entusiasmo ao ver aplicado nos produtos as padronagens apresentadas. $O$ ensejo de aliar o design de superfície à cultura e tradição gaúcha foi alcançado, tendo em vista também que as estampas foram aplicadas nos modelos de bolsas propostos de modo satisfatório. $O$ consumo das grandes massas tem crescido consideravelmente, e isso demanda grande esforço dos designers e demais profissionais das áreas interligadas para acompanhar o ritmo evolutivo de forma eficaz e responsável acerca do meio ambiente. O novo milênio trouxe consigo releituras de modismos passados, entretanto, foi necessário pensar à frente, de modo que, o conceito e a concepção do projeto andam interligados com questões ecológicas, por exemplo. Este ponto foi essencial para a elaboração do objetivo deste estudo, onde os produtos deveriam receber as estampas elaboradas de forma funcional e estética.

\section{REFERÊNCIAS}


AGOSTINI, Angélica. Design de superfície aplicado ao segmento de homewear. Universidade do Oeste de Santa Catarina, Xanxerê, RS, 2010.

BARROSO, Cátia R. Ação design consciente. Disponível na internet por http em: <http://kriyadesign.com.br/kd/design-consciente.php> Acesso em: 15 dez. 2013.

CHATAIGNIER, Gilda. Fio a fio: tecidos, moda e linguagem. São Paulo: Estação das Letras, 2006.

CONSOLO, Cecília. (Org.) Anatomia do design: uma análise do design gráfico brasileiro. São Paulo: Blücher, 2009.

COSTA, Dhora. A história das bolsas. São Paulo: Matrix, 2010.

FREITAS, Renata Oliveira Teixeira de. Design de Superfície: ações comunicacionais táteis nos processos de criação. São Paulo: Blucher, 2011.

GOMES, Marcelo Bolshaw. A cultura como dupla mediação social e a tese das três mudanças estruturais na sociedade contemporânea. Contrapontos. Itajaí, SC, v. 5, n. 1, p. 109-124, 2005.

GORDON, Bob; GORDON, Maggie. O essencial do design gráfico. [Tradução: Ilka Maria Santi]. São Paulo: Senac São Paulo, 2012.

LUPTON, Ellen; PHILLIPS, Jennifer Cole. Novos fundamentos do design. [Tradução: Cristian Borges]. São Paulo: Cosac Naify, 2008.

OLIVEN, R. J. A parte e o todo: a diversidade cultural no Brasil-Nação. Petrópolis: Vozes, 1992.

PEZZOLO, Dinah Bueno. Tecidos: história, tramas, tipos e usos. São Paulo: Senac São Paulo, 2007.

RUBIM, Renata. Desenhando a superfície. São Paulo: Rosari, 2005.

RÜTHSCHILLING, Evelise Anicet. Design de Superfície. Porto Alegre: UFRGS, 2008.

SCHWARTZ, Ada Raquel Doederlein; Design de Superfície: abordagem projetual geométrica e tridimensional. Bauru, SP, 2008. Dissertação (Mestrado Desenho Industrial) - Faculdade de Arquitetuta, Artes e Comunicação - Universidade Estadual Paulista.

SILVA, Wallace Pereira. A Substituição de Sacolas Plásticas nos Supermercados e a Atitude do Consumidor: um estudo de caso na cidade de Taguatinga - DF. Universidade de Brasília, Brasília, DF, 2011.

TUBINO, Wilson. Guia prático do chimarrão. Porto Alegre: Martins Livreiro Editora, 2011.

UDALE, Jenny. Tecidos e Moda - Coleção Fundamentos do Design de Moda. Porto Alegre: Bookman, 2009. 